and D. George (eds.)

\title{
Redescription of two species of Neanthes (Polychaeta: Nereididae) possessing a large notopodial prechaetal lobe
}

\author{
TORKILD BAKKEN \\ Section of Natural History, Norwegian University of Science and Technology, NO-7491 Trondheim, Norway. \\ E-mail: torkild.bakken@vm.ntnu.no
}

\begin{abstract}
SUMMARY: Phylogenetic analyses of "nereidids with paragnaths" indicated that species currently assigned to Neanthes sensu lato possessing a notopodial prechaetal lobe as large as the notopodial dorsal and ventral ligules were grouped in a separate clade with uncertain relationships to nominal Neanthes taxa. Further studies of these species are required to test this theory. Literature studies and examination of material alike prove that redescriptions of several species are needed until phylogenetic analyses can be undertaken. To meet this goal material from two species is included here for redescription, being necessary to reveal as many details as possible for a forthcoming phylogenetic analysis. Neanthes bongcoi Pillai, 1965 was originally described from the Philippines and is redescribed based on a quantity of specimens. It is here reported to be common in northern Australian waters. Neanthes meggitti Monro, 1931 is redescribed based on type material and a lectotype is designated for $N$. meggitti. Both $N$. bongcoi and N. meggitti are characterised by presence of a notopodial lobe as large as dorsal and ventral notopodial ligules in anterior chaetigers. Relevance to similar characteristics in related species is discussed.
\end{abstract}

Keywords: Polychaeta, Nereididae, Neanthes meggitti, Neanthes bongcoi, taxonomy.

RESUMEN: REDESCRIPCIÓN DE DOS ESPECIES DE NEANTHES (POLYCHAETA: NEREIDIDAE) QUE POSEEN UN GRAN LÓBULO NOTOPODIAL PRESETAL. - Los análisis filogenéticos sobre nereídidos con paragnatos han revelado que las especies normalmente asignadas a Neanthes sensu lato son poseedoras de un lóbulo notopodial presetal, el cual es tan largo como las lígulas notopodiales dorsales y ventrales. Por esta razón, dichos nereididos han sido agrupados en un clado aparte, con inciertas relaciones con respecto al resto de las especies nominales de Neanthes. Estudios exhaustivos de estas especies son necesarios para validar esta teoría. Las revisiones bibliográficas y el examen de material demuestran igualmente que la redescripción de algunas especies es necesaria hasta que los análisis filogenéticos puedan ser desarrollados. Con esta finalidad, se incluye en el presente trabajo la redescripción de dos especies con el máximo de detalle posible con el objetivo de realizar un próximo análisis filogenético. Neanthes bongcoi Pillai, 1965 fue originalmente descrita para Filipinas y es redescrita sobre la base de un grupo de ejemplares. Los registros de esta especie son frecuentes en aguas del norte de Australia. Neanthes meggitti Monro, 1931 es redescrita a partir del material tipo. Se designa un lectotipo para N. meggiti. Ambas especies, N. bongcoi y N. meggitti, se caracterizan por la presencia en los setígeros anteriores de un lóbulo notopodial, el cual es tan grande como las lígulas notopodiales dorsales y ventrales. Finalmente, se comentan estas características en especies relacionadas.

Palabras clave: Polychaeta, Nereididae, Neanthes meggitti, Neanthes bongcoi, taxonomía.

\section{INTRODUCTION}

The family Nereididae consists of several large genera of which some are known to be heterogeneous groups of species. Among these genera, species that have been assigned to Neanthes
Kinberg, 1865 have been delineated in informal groups based on chaetal and parapodial characters (Fauchald, 1972; Wilson, 1984). Examination of a number of nereidid taxa with paragnaths has shown that several morphological characters, especially parapodial characters, need to be emphasised to a 
larger degree than has been usual in previous descriptions. Recent phylogenetic analyses of the traditionally recognised subfamily Nereidinae showed that Neanthes is not a monophyletic group (Bakken and Wilson, 2005). Targeting the subfamily Nereidinae as defined by Fitzhugh (1987), their results showed that Neanthes-species included in the analyses were paraphyletic, but also revealed that more knowledge of character homology is needed. Hence more data from described species of Neanthes is needed before phylogenetic analyses of Neanthes as a group can take place.

One parapodial character that has been shown to have important information is the notopodial prechaetal lobe, the size of the lobe and the range measured in a number of chaetigers along the body. The focus in this case is on the notopodial prechaetal lobe being "as large as dorsal and ventral notopodial ligules in anterior chaetigers", and if present "present throughout" or "restricted to anterior chaetigers" (Wilson et al., 2003). The common feature is that the size is reduced in posterior chaetigers. Similarly a prechaetal lobe can be smaller than the notopodial ligules in anterior chaetigers or absent altogether. Results from the nereidine phylogenetic analyses (Bakken and Wilson, 2005) illustrated how the included taxa with a large notopodial prechaetal lobe were placed in one clade, with uncertain relationships to nominal Neanthes taxa. Although no confirmed conclusions are drawn from this, as more taxa will have to be included to show the phylogenetic relationships between different taxa, it poses interesting questions about relationship and character homology.

Presence of a dorsal notopodial ligule expanded in breadth was demonstrated to be a synapomorphy for Alitta virens (Sars, 1835) and Alitta succinea (Leuckart, 1847) based on phylogenetic analyses (Bakken and Wilson in press: Fig. 6B). Along with the closely related species Alitta brandti Malmgren, 1866 and Alitta grandis (Stimpson, 1853) (Khlebovich, 1996) these two also share the presence of a large prechaetal lobe throughout the body. In Neanthes bongcoi Pillai, 1965 and Neanthes meggitti Monro, 1931 the dorsal notopodial ligule is not expanded in posterior chaetigers, and the prechaetal lobe is restricted to a number of anterior chaetigers. However, variation may be due to size of specimens, as has previously been demonstrated in specimens smaller than $1 \mathrm{~mm}$ in body width, where parapodial characters may be poorly developed (Wilson, 1984).
Being a sister group to $A$. succinea and A. virens (Bakken and Wilson, 2005) Neanthes cricognatha Ehlers, 1904 is similar to these in possessing a large prechaetal lobe throughout the body but does not have an enlarged dorsal ligule. A striking feature for $N$. cricognatha and two similar species that might be a species complex, Neanthes caudata (delle Chiaje, 1825) and Neanthes arenaceodentata (Moore, 1903), is the presence of paragnaths in Areas V-VIII joined in a single band (Wilson, 1984), a character that separates $N$. cricognatha from both $A$. virens and A. succinea, and also from N. boncoi.

Possession of a large notopodial prechaetal lobe is, however, not unique to taxa from Neanthes sensu lato, as it also occurs in Leonnates spp. demonstrating that it is a homoplasious character. This will not be discussed further here, as the aim of this paper is to redescribe $N$. bongcoi and $N$. meggitti to complement data for future phylogenetic analyses.

\section{MATERIALS AND METHODS}

Specimens were taken from museum material. The following abbreviations for museums and institutions are used: AM (Australian Museum, Sydney, Australia), MAGNT (Museum and Art Gallery of Northern Territory, Darwin, Australia), NHM (Natural History Museum, London, UK).

Descriptions were generated from a DELTA database (Dallwitz, et al. 1993 onwards) of Nereididae (Wilson, et al. 2003) updated with new information from examined material.

For characters relating to parapodia the terminology of Hylleberg et al. (1986) has been used, following later modifications by Hutchings and Reid (1990), Glasby (1999) and Bakken (2002) as implied in the Nereididae DELTA database (Wilson et al., 2003). End-view drawings of parapodia (Fig. 1B-D; Fig. 3A-E) follow the style of Hylleberg et al. (1986: Fig. 1).

\section{TAXONOMIC ACCOUNT}

Neanthes bongcoi Pillai, 1965

(Fig. 1A-E)

Neanthes bongcoi Pillai, 1965: 142-144, fig. 12a-j.

Material examined: Shirley Island, WA, Australia, $16^{\circ} 17^{\prime} \mathrm{S}$ $123^{\circ} 26^{\prime} \mathrm{E}, 1988-07-26$, mangrove to sand and reef, coll. P.Hutchings, AM W19476 (1); Sandy Cay on Port George, WA, 
Australia, $15^{\circ} 20^{\prime} \mathrm{S} 124^{\circ} 39^{\prime} \mathrm{E}, 1988-07-12$, dredging, coll P.Hutchings, AM W19478 (1); Calliope River, Qld, Australia, $23^{\circ} 51^{\prime} \mathrm{S} 151^{\circ} 10^{\prime} \mathrm{E}, 1974-1983$, Gladstone survey, QLD elec comm, coll. P.Saenger, AM W199365 (31); Bush Bay, WA, Australia, $25^{\circ} 11^{\prime} \mathrm{S} 113^{\circ} 48^{\prime} \mathrm{E}, 1984-01-06$, sieved sand from waters edge, coll. H.Stoddart, AM W19867 (1); Mangrove Point, Broome, WA, Australia, stn BR 6/6, depth LSW, 1984-09-30, underside of stones, coll. R.Hanley, MAGNT W2260 (1); Darwin Harbour, NT, Australia, CRIMP survey, stn NTDPWP, Aug 1998, MAGNT (2); Darwin Harbour, NT, Australia, CRIMP survey, stn NTDCBM, Aug 1998, MAGNT (7); Darwin Harbour, Catalina wreck A24, NT, Australia, intertidal, coll. C.Glasby ref.no CG 00/02, MAGNT (1); West side of Barrow Point, Port Ess., NT, Australia, stn CPV8, depth LSW, 1985-09-18, mudflat in front of mangrove, MAGNT W3476 (2); Vic. settlement, Port Ess., NT, Australia, stn CPV2, depth MLW, 1985-09-11, sandy beach, MAGNT W3317 (1); Trip 18-864 A/2, stn 3A, 1972-05-19, coll. NT fisheries, MAGNT W1376 (1)

Description. Frontal antennae present, one pair, cirriform, as long as palps (Fig. 1A); palpophore with transverse groove present, palpostyles conical. Prostomium with entire anterior margin, longer than wide (Fig. 1A), usually pigmented. Eyes present, two pairs. One apodous anterior segment, greater than length of chaetiger 1, usually with a dark brown pigmented band. Four pairs of tentacular cirri present. Tentacular cirri with distinct cirrophores, longest tentacular cirri extend back to chaetiger 6-8. Jaws with dentate cutting edge, yellow to brown with 7-8 teeth. Maxillary ring of pharynx with paragnaths arranged in discrete areas. Paragnath counts: Area $I=0-1$ conical paragnaths (usually 1 ); Area II $=4-10$ conical paragnaths in two rows in an arc; Area III = 3-10 conical paragnaths in one transverse row; Area IV = 5-13 conical paragnaths present in two longitudinal rows, smooth bar-like paragnaths absent. Area V and VI present as distinct groups. Area V =0; Area VI = 1-6 conical paragnaths arranged in a roughly circular group; Areas VII-VIII = 4-17 conical paragnaths, similar in size, arranged in one line. Paragnaths on the oral ring with a pointed tip.

Notopodium with at least one distinct ligule or lobe. Dorsal notopodial ligule present, triangular with a pointed tip (Fig. 1B) as long as notopodial

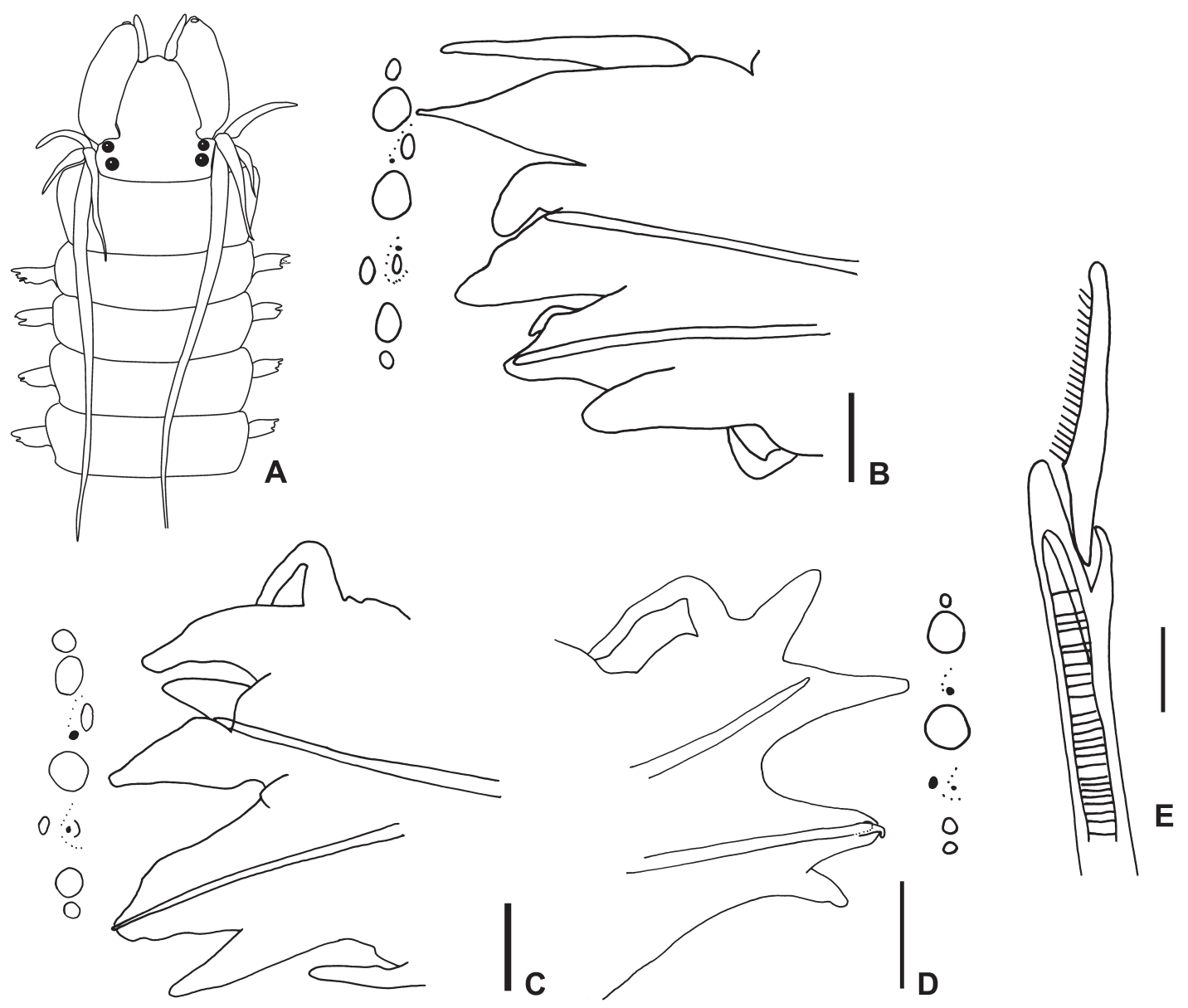

FIG. 1. - Neanthes bongcoi Pillai, 1965: A, anterior end, dorsal view; B, parapodium chaetiger 12 anterior view; C, parapodium chaetiger 21 anterior view; D, parapodium chaetiger 55 posterior view; E, heterogomph falciger from neuropodial ventral fascicle chaetiger 21 . Scale bar $\mathrm{B}-\mathrm{D}=0.1 \mathrm{~mm}, \mathrm{E}=0.01 \mathrm{~mm}$. End-view drawings of parapodia in B-D are not to scale. A is redrawn from Pillai (1965: Fig. 12A), B-E from AM W19476. 
ventral ligule throughout, and of similar length throughout. Notopodial prechaetal lobe present on anterior chaetigers, approximately equal to length of dorsal notopodial ligule in anterior chaetigers (Fig. 1B); reducing in size from about chaetiger 20 (Fig. 1C), last present at about chaetiger 50 (Fig. 1D). Ventral notopodial ligule rounded triangular, similar throughout. Dorsal cirrus 1-1.5 times as long as dorsal notopodial ligule in anterior chaetigers; basally attached to dorsal ligule throughout all chaetigers.

Neuropodium with prominent inferior lobe in anterior chaetigers, less developed posteriorly. Neuropodial postchaetal lobe present (Fig. 1B-C, end-view), projecting beyond acicular ligule, digitiform; present throughout but decreasing in size posteriorly. Ventral neuropodial ligule digitiform, similar in length to acicular ligule; slightly shorter than acicular ligule in posterior chaetigers. Ventral cirri short.

Notoaciculae absent from chaetigers 1 and 2 . Notochaetae homogomph spinigers present throughout. Neurochaetae dorsal fascicle: homogomph spinigers present, heterogomph falcigers present on anterior and posterior chaetigers, blades serrated. Neurochaetae ventral fascicle: heterogomph spinigers present, heterogomph falcigers with long blades present in anterior and posterior chaetigers (Fig. 1E). Anal cirri cirriform, cirri extending back 7-10 chaetigers.

Remarks. The prostomium in the examined specimens has dark pigmentation often covering most of the prostomium, the peristomium has a transversal dark brown band, and intersegmental brown spots on the up to first 11 chaetigers. This pigmentation pattern varied from light to dark brown, or could be almost absent. Similarly the number of segments with pigmentation would also be subject to variation. No differences in morphological features were observed in the Australian material, and the Australian specimens agree well with the original description given by Pillai (1965). They differ only in the number of paragnaths in Area IV which are fewer in number (4 or 5) than the Australian material examined here (5-13).

It seems that the range of the notopodial prechaetal lobe is dependent of the size of the specimen. In larger specimens $(2 \mathrm{~mm}$ body width at chaetiger 10 excluding parapodia) the prechaetal lobe is present throughout, but becomes smaller from chaetiger 20-25 and diminishes posteriorly to a very small lobe in the posteriormost chaetigers. In smaller specimens (up to $1 \mathrm{~mm}$ body width) the prechaetal lobe is absent from about chaetiger 45-50 (Fig. 1D; end-view).

Neanthes bongcoi most closely resembles $N$. cricognatha to which it shares the characteristic preand postchaetal lobes in noto- and neuropodia respectively. Neanthes cricognatha, however, has paragnaths on the oral ring in one continuous band not separating Areas V-VIII. Neanthes bongcoi is also similar to Neanthes chilkaensis Southern, 1921, but can be distinguished from this by the shorter notopodial prechaetal lobe in the latter species, and the paragnath pattern (especially by the two rows in Areas VII-VIII in N. chilkaensis (Southern, 1921) compared with only a few conical paragnaths arranged in one row in $N$. bongcoi). The recently described Neanthes philippinensis de LeónGonzález and Salazar-Vallejo, 2003 is similar in having a large prechaetal notopodial lobe of the same size as the dorsal notopodial ligule, but is clearly restricted to a number of anterior chaetigers: unfortunately their description (de León-Gozalez and Salazar-Vallejo, 2003) fails to record this in detail. Neanthes philippinensis also has quite different heterogomph falcigers with the blade possessing a distal tendon, which is not observed in $N$. bongcoi.

It was not possible to arrange for a loan of the holotype of N. bongcoi for this study. A single specimen in the NHM representing the paratype must at some stage have been misplaced. The supposed paratype did not correspond to the original description (Pillai 1965), but rather represents an unidentified species. This fact was also reported by de LeónGozalez and Salazar-Vallejo (2003). Until the whereabouts of the holotype can be established no further action can be taken.

Habitat. The species occurs in sand with fine coral rubble, from the intertidal to a depth of $20 \mathrm{~m}$, and on mudflats in front of mangroves.

Distribution. Dagupan City, Luzon, Philippines (type locality) (Pillai, 1965). Australia: Broome, Western Australia; Darwin Harbour, Northern Territory; Calliope River, Queensland.

Neanthes meggitti Monro, 1931 (Figs. 2, 3A-G)

Nereis (Neanthes) meggitti Monro, 1931: 580-585, figs. 1-6.

Material examined: Syntypes, Latter St. jetty, Rangoon River, Rangoon, 1931-01-15, leg. F.S. Meggitt, NHM 1931.6.22.71-73 (7). 


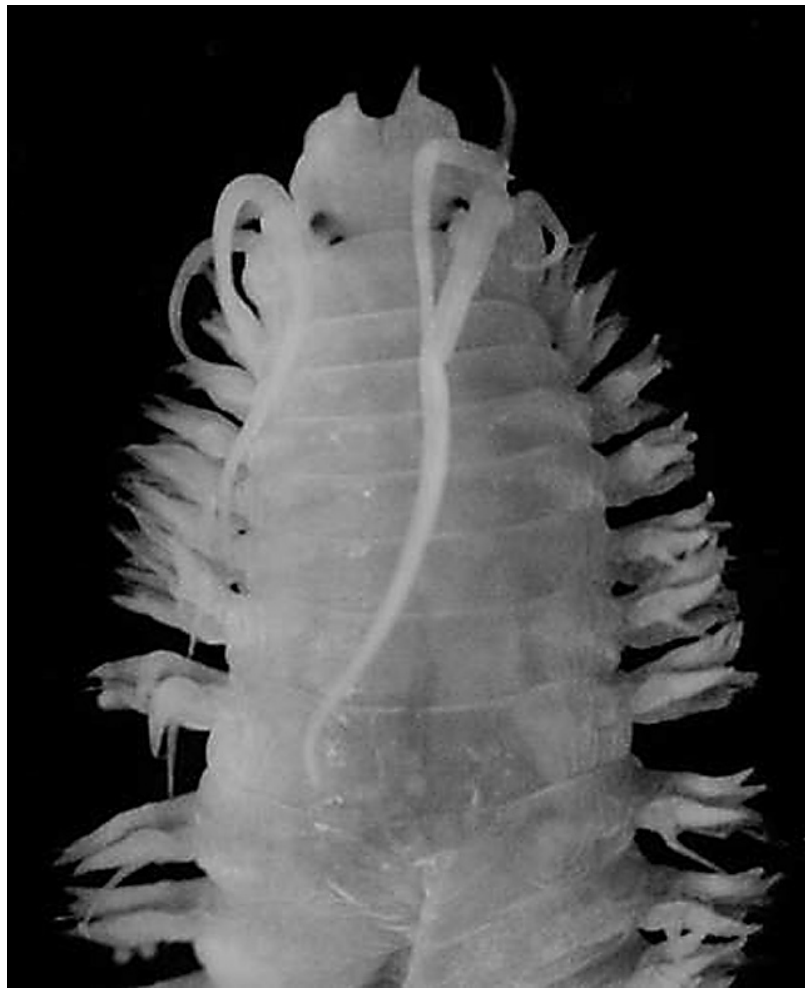

FIG. 2. - Neanthes meggitti Monro, 1931 NHM 1931.6.22.71-73, anterior end dorsal view. The specimen photographed measured $1.5 \mathrm{~mm}$ body width excluding parapodia at chaetiger 10 .

Description. The larger specimen in the type series is designated as a Lectotype, the remaining specimens are accordingly paralectotypes. The Lectotype is an incomplete specimen measuring 30 $\mathrm{mm}$ long for 62 chaetigers, $1.5 \mathrm{~mm}$ body width at chaetiger 10 excluding parapodia. Paragnath counts: Area I $=4$; Area II: $14 / 15$; Area III $=24$; Area IV = 20/22; Area V = 7; Area VI = 5/6; Areas VII-VIII = 71. The following description encompasses all specimens.

Frontal antennae present, one pair cirriform, shorter than palps; palpophore with transverse groove present, palpostyles conical. Prostomium with entire anterior margin, wide as long oval shape (Fig. 2). Eyes present, two pairs. One apodous anterior segment, greater than length of chaetiger 1 (Fig. 2). Four pairs of tentacular cirri present, tentacular cirri with distinct cirrophores, longest tentacular cirri extend back to chaetiger 8-9. Jaws with dentate cutting edge, stout dark brown, with 5 teeth. Maxillary ring of pharynx with paragnaths arranged in discrete areas. Paragnath counts: Area $I=3-4$ conical paragnaths in a longitudinal line; Area II = 10-15 conical paragnaths in 2-3 diagonal rows; Area III = 17-24 conical paragnaths in 3-4 transverse rows; Area IV = 16-23 conical paragnaths, 2-3 rows in an arc, smooth bar-like paragnaths absent. Areas $\mathrm{V}$ and VI present as distinct groups. Area $\mathrm{V}=3-7$ conical paragnaths arranged in a triangular pattern; Area VI $=4-6$ conical paragnaths arranged in a roughly circular group; Areas VII-VIII = 65-71 large conical paragnaths, similar in size and arranged in 45 rows.

Notopodium with at least one distinct ligule or lobe. Dorsal notopodial ligule present, long and slender with a pointed tip (Fig. 3A-C), as long as ventral ligule, similar throughout. Notopodial prechaetal lobe present from chaetiger 3, long and slender approximately equal to length of dorsal notopodial ligule in anterior chaetigers (Fig. 3A-B), reducing in size posteriorly from about chaetiger 30 (Fig. 3C), last present at about chaetiger 45 (Fig. 3D). Ventral notopodial ligule long and slender, similar throughout. Dorsal cirri single, basally attached to dorsal ligule throughout all chaetigers, 1.5 times length of ventral notopodial ligule in first 20 chaetigers, then as long as dorsal ligule, again longer than in posteriormost chaetigers (Fig. 3D) (from about chaetiger 50 ).

Neuropodium with prominent inferior lobe in anterior and mid-body chaetigers, less developed posteriorly. Neuropodial postchaetal lobe present from chaetiger 15 (Fig. 3B-C, end-view), present as a low digitiform lobe not projecting beyond end of acicular ligule, reducing in size posteriorly, last present on chaetigers 50 (Fig. 3C-D, end-view). Ventral neuropodial ligule digitiform, as long as neuropodial acicular ligule, slightly longer than acicular ligule in posterior chaetigers (Fig. 3C-D). Ventral cirri single, shorter than neuropodial acicular ligule.

Notoaciculae absent from chaetigers 1 and 2 . Notochaetae homogomph spinigers. Neurochaetae, dorsal fascicle: homogomph spinigers, heterogomph falcigers present throughout (Fig. 3F), blades serrated. Neurochaetae, ventral fascicle: heterogomph spinigers, with blades finely serrated proximally, heterogomph falcigers with medium long blades present in anterior and posterior chaetigers (Fig. $3 \mathrm{G})$. Blade of ventral fascicle heterogomph falcigers with a single terminal tooth, in posterior chaetigers with distal tendon (Fig. 3G).

Epitokal modified parapodia (observed in one male specimen) from chaetiger 18, anterior parapodia (from chaetiger 14) with a large neuropodial postchaetal lobe (Fig. 3E). 


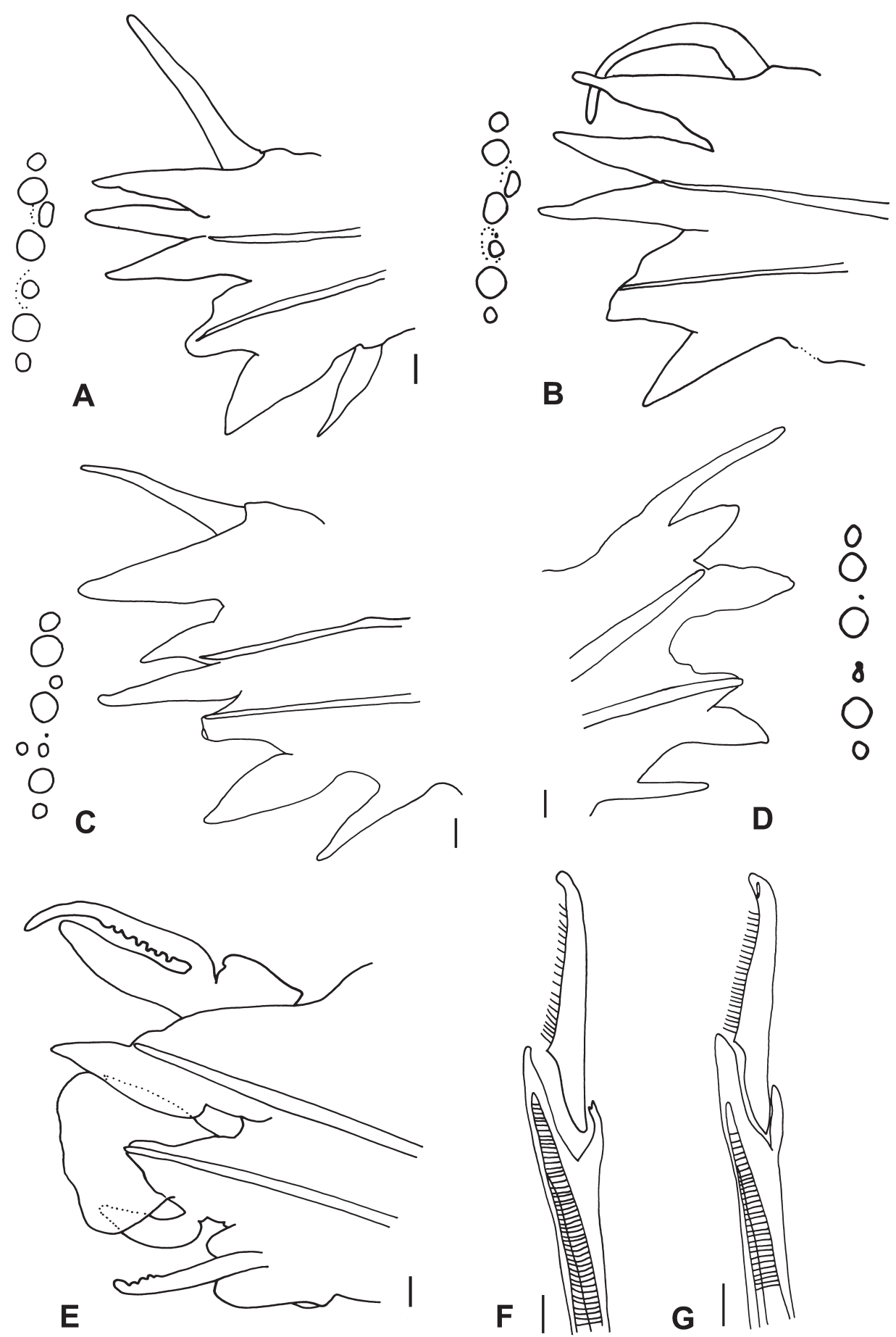

FIG. 3. - Neanthes meggitti Monro, 1931 NHM 1931.6.22.71-73 Lectotype: A, parapodium chaetiger 4 anterior view; B, parapodium chaetiger 12 anterior view; $\mathrm{C}$, parapodium chaetiger 30 anterior view; D, parapodium chaetiger 55 posterior view; E, parapodium chaetiger 38 anterior view, from epitokous male; $\mathrm{F}$, heterogomph falciger from neuropodial dorsal fascicle chaetiger 4; G, heterogomph falciger from neuropodial ventral fascicle chaetiger 10 . Scale bar $A-E=0.1 \mathrm{~mm}, \mathrm{~F}-\mathrm{G}=0.01 \mathrm{~mm}$. End-view drawings of parapodia in A-E are not to scale.

Remarks. A lectotype is designated here for $N$. meggitti. All seven specimens in the type series are in very good condition. The specimens are mature, five atokous and in addition there is one specimen labelled "atokous female", and finally a specimen labelled "epitokous male".
General appearance of the examined specimens is somewhat "bushy" at the anterior end with long parapodial appendages. The presence of long and slender notopodial prechaetal lobes as long as dorsal and ventral notopodial ligules in anterior chaetigers indicates that a large neuropodial postchaetal lobe 
should be present. This is usually observed in taxa with similar features starting on the first 2-5 chaetigers and is a common feature (personal observations). This is, however, not the case, a postchaetal lobe is present but only as a small lobe not projecting beyond the acicular ligule, and starting on chaetiger 15 . It should be mentioned that most chaetae were broken in all specimens but it was still possible to observe chaetal characters, although observations on some variation might have been lost.

The parapodial characteristics of $N$. meggitti make it unique. This is illustrated by the large notopodial prechaetal lobe obviously restricted to a number of anterior chaetigers, in combination with the small neuropodial postchaetal lobe being restricted to a number of chaetigers commencing at chaetiger 15 .

Distribution. Type locality: Rangoon River, Rangoon, Myanmar, 40 miles $(64 \mathrm{~km})$ from the mouth of the river (Monro 1931). Observations from India have been discussed by Nageswara Rao (1977).

\section{ACKNOWLEDGEMENTS}

The following persons are thanked for loans and access to their collections: Penny Berents and Pat Hutchings (AM), Chris Glasby (MAGNT), Alex Muir, Gordon Paterson and Emma Sherlock (NHM). Robin Wilson provided working facilities at Museum Victoria, Australia. I am grateful to Jorge Núñes and two anonymous referees for comments on the manuscript. Financial support was provided through a visit to NHM by SYS-RESOURCE at the Natural History Museum, London through the European Commission IHP Programme EU; and by a visiting scholarship to Melbourne, Australia from the Research Council of Norway NFR 151548/432.

\section{REFERENCES}

Bakken, T. - 2002. A new species of Neanthes (Polychaeta: Nereididae) from southern Australia. Mem. Mus. Victoria, 59: 327-331.

Bakken, T. and R.S. Wilson. - 2005. Phylogeny of nereidids (Polychaeta, Nereididae) with paragnaths. Zool. Scr., 34: 507-547.

Dallwitz, M.J., T.A. Paine and E.J. Zurcher. - (1993 onwards). User's guide to the DELTA system: a general system for processing taxonomic descriptions. 4th edition. http://biodiversity.uno.edu/delta/

de León-González, J.A. and S.I. Salazar-Vallejo. - 2003. Four new nereidid species (Annelida, Polychaeta) collected during the MUSORSTOM cruises in the Indo-Pacific Ocean. Zoosystema, 25: 365-375.

Fauchald, K. - 1972. Benthic polychaetous annelids from deep water off Western Mexico and adjacent areas in the eastern Pacific Ocean. Allan Hancock Monogr. Mar. Biol., 7: 1-575.

Fitzhugh K. - 1987. Phylogenetic relationships within the Nereididae (Polychaeta): implications at the subfamily level. Bull. Biol. Soc. Wash., 7: 174-183.

Glasby, C.J. - 1999. The Namanereidinae (Polychaeta: Nereididae). Part 1, taxonomy and phylogeny. Rec. Aust. Mus., Suppl., 25: 1-129.

Hutchings, P. and A. Reid. - 1990. The Nereididae (Polychaeta) from Australia - Gymnonereidinae sensu Fitzhugh, 1987: Australonereis, Ceratocephale, Dendronereides, Gymnonereis, Nicon, Olganereis and Websterinereis. Rec. Aust. Mus., 42: 69-100.

Hylleberg, J., A. Nateewathana and A. Bussarawit. - 1986. Polychaetes of Thailand. Nereididae (part 1): Perinereis and Pseudonereis with notes on species of commercial value. Phuk. Mar. Biol. Center Res. Bull., 43: 1-22.

Khlebovich, V.V. - 1996. Polychaetes of the family Nereididae of the Russian seas and the adjacent area. Fauna of Russia and neighbouring countries. Polychaetous Annelids. 3, "Nauka" Publishing House, St. Petersburg.

Monro, C.C.A. - 1931. A new brackish-water polychæte from Rangoon, Nereis (Neanthes) megetti sp.n. Ann. Mag. Nat. Hist., 8: $580-585$.

Nageswara Rao, C.A. - 1977. On the occurrence of Nereis (Neanthes) meggitti Monro (Polychaeta, Annelida) in Indian waters. Sci. Cult., 43(11): 493-495.

Pillai, T.G. - 1965. Annelida Polychaeta from the Philippines and Indonesia. Ceylon J. Sci. (Biol. Sci.), 5: 110-177.

Southern, R. - 1921. Polychaeta of the Chilka Lake and also of fresh and brackish waters in other parts of India. Mem. Indian Mus., 5: 563-659.

Wilson, R.S. - 1984. Neanthes (Polychaeta: Nereididae) from Victoria with descriptions of two new species. Proc. Roy. Soc. Victoria, 96: 209-226.

Wilson, R.S., T. Bakken and C.J. Glasby. - 2003. Nereididae (Polychaeta)-A DELTA database of genera, and Australian species. In: R.S. Wilson, P.A. Hutchings and C.J. Glasby (eds.), Polychaetes: An Interactive Identification Guide. CSIRO Publishing, Melbourne.

Received August 31, 2004. Accepted May 11, 2005. 
